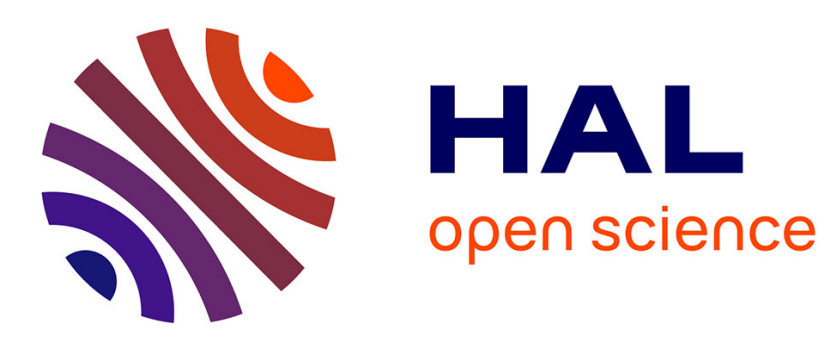

\title{
The Self and the Subject: A Psychoanalytic Lacanian Perspective
}

Stéphane Thibierge, Catherine Morin

\section{To cite this version:}

Stéphane Thibierge, Catherine Morin. The Self and the Subject: A Psychoanalytic Lacanian Perspective. Neuropsychoanalysis, 2010, 12 (1), pp.81-93. 10.1080/15294145.2010.10773632 . hal-01519835

\section{HAL Id: hal-01519835 \\ https://hal.science/hal-01519835}

Submitted on 3 Jul 2017

HAL is a multi-disciplinary open access archive for the deposit and dissemination of scientific research documents, whether they are published or not. The documents may come from teaching and research institutions in France or abroad, or from public or private research centers.
L'archive ouverte pluridisciplinaire HAL, est destinée au dépôt et à la diffusion de documents scientifiques de niveau recherche, publiés ou non, émanant des établissements d'enseignement et de recherche français ou étrangers, des laboratoires publics ou privés. 


\title{
The Selfand theSubject:A Psychoanalytic Lacanian Perspective
}

\author{
S. Thibierge \& C. Morin (Paris)
}

In current research, the self, or the "first-person perspective," is often studied in terms of its cognitive functions (agency, "mindreading," body representation, etc.). As clearly shown by Decety (2002), these studies are based on the assumption that mental processes must be "described in terms that make it clear that they are achievable by one brain." It has been well established, however, that though one human brain is necessary, it is not sufficient for the development of a psychic subject capable of mental processes. Indeed, to do so, the brain must be connected with a particular language system, which is external and exists prior to the birth of each human brain. Psychoanalysis demonstrates that such a process not only yields human individuals who consider themselves as autonomous egos with a cognitive representation of the external world, but that these humans also suffer a particular "lack" or "want," which makes each of them a desiring subject. Regardless of the conscious representations of the "self," the psychic life (including cognition) of this subject is governed by the repeated-though vain-search for a repressed object that cannot be represented. The contribution of psychoanalysis to understanding what constitutes the "self" was first indirectly demonstrated through the psychoanalysis of neurotic patients. The study of psychiatric or neurological pathologies, in particular psychosis (Cotard, Fregoli, and Capgras syndromes) or the right hemisphere syndrome (in particular, somatoparaphrenia) confirms these findings. This paper represents a contribution to the understanding of subjectivity through a psychoanalytic perspective on the Fregoli syndrome and somatoparaphrenia.

Keywords: self, specular image, body image, identification, misidentification, somatoparaphrenia

The entry for "self" in the Penguin Dictionary of Psychology reads: "One of the more dominant aspects of human experience is the compelling sense of one's unique existence, what philosophers have traditionally called the issue of personal identity or of the self." The term "self" is thus both a philosophical issue and, for each of us, a compelling evidence. It has been secondarily introduced in psychoanalytic speculations after and independently of Freud. Jung (1958) used the term to refer to the "archetype of the transcendental totality," an acceptance that is much more philosophical than psychoanalytic. Melanie Klein used the term in such an imprecise manner that it might either be equivalent to ego in her own texts (see Klein, 1946, p.

144) or considered by her readers as characterizing "all the drives and feelings of the whole personality" (see, for example, Chemama, 2000, p. 310). This vagueness seems to have encouraged a variety of uses in other psychoanalytic works. In Winnicott's thought (1967), the self is characterized by its ambiguous relation to the mother's body and representations, from which the subject has to separate, while maintaining a symbolic link to the mother's representations; according to Winnicott, this link makes the self a place where to seek refuge, to be able to relax, to feel that one is real. In Kohut's works, the term seems to refer to the unconscious component of the ego; the ego should, in the course of psychoanalytic treatment, metabolize and master the self (Kohut, 1971). This self-psychology thus tends to be confused with ego-psychology.

In neuropsychological research, the term "self" is used without any attempt to characterize what the self is. Most studies consist of using neuroimagery to assess the variations of brain metabolism in mental states, psychological or neuropsychological functions that are supposed to be involved in a first-person perspective

S. Thibierge: UFR Sciences Humaines et Cliniques, Université Paris Diderot, Paris, France; C. Morin: Hôpital Pitié-Salpêtrière, Service de Médecine Physique et Réadaptation, Paris, France

Correspondence to: S. Thibierge, CRPM-EAD 3522, UFR Sciences Humaines et Cliniques- Université Paris Diderot, 26 rue de Paradis, 75463 Paris Cedex 10, France (email: stephane.thibierge@wanadoo.fr) 
(1PP). In their review, Vogeley and Fink (2003) successively consider spatial cognition, distinction between one's own and others' intentions to act, "mindreading," and body representation, to end with a hypothetical self-reference, resting state. The aim of these descriptive studies is to localize the brain structures involved in self-consciousness. Vogeley and Fink (2003) thus write: "With respect to cognitive neuroscience, the question of the self can be reformulated as: which neural ensembles underlie (and may thus be responsible for) the 'subjective' nature of those mental and bodily states that are candidates for self-consciousness?" (p. 42). While the quotation marks around subjective suggest that self-consciousness might not be subjective in nature, the authors do not consider it necessary to tell us what the self is. Newen and Vogeley (2003) identify a "neural signature of the self" by listing the neural structures activated during activities that involve a 1PP. However, as underlined by Legrand (2003), this approach does not consider the fact that "to have a 1PP, is, primarily, to live through it, i.e., to perceive and act according to it." In other words, to paraphrase Thomas Nagel (1974), this approach does not address the question "what it is like to be or to have a self?" Jeannerod (2003) perhaps touches this point when he claims that "Even though the distinction between the self and the other is performed by adults without any difficulty (our emphasis), it may become problematic under pathological circumstances." Indeed, one could say that human subjects do not perform this distinction at all; each of us is rather convinced-without even thinking of it - that he or she has or is a self - that is, that he or she is a unique, autonomous, identifiable being, different from other beings, with cognitive abilities and coherent psychological properties. In ordinary, nonpathological circumstances, this conviction is only implicit. However, making this conviction explicit is currently the ordinary mode of investigating the 1PP. For example, Johnston et al. (2002) ask their participants to respond to a variety of statements requiring knowledge of and reflection on their own abilities, traits, and attitudes (e.g., "I forget important things," "I'm a good friend," "I have a quick temper").

In contrast to neuropsychology, psychoanalysis precisely questions our ordinary implicit conviction of being unique and autonomous individuals. On the one hand, psychoanalysis makes it questionable whether the autonomy of the talking being is actually self-evident under normal circumstances. For example, when an adult commits a slip of the tongue, the words he pronounces - indisputably his self-production - sound foreign to his self-consciousness, even if coming from no other talking being. This everyday life example shows that our certitude to be, so to say, "our own" selves does not guarantee either our coherence or our autonomy. Freud was the first to reveal, and insist on, the subordination and the heterogeneity of the human subject. This is precisely what is revealed by the four main phenomena that give access to the unconscious (dreams, symptoms, and slips of the tongue and other parapraxes). On the other hand, Freud did not situate a self in the various aspects of our personal identity that he described: (1) the ego-ideal takes its origin in the voice and the regard of parents and educators; (2) the ideal ego is a self-representation secondarily cathected by the primarily autoerotic libido (Freud, 1914); (3) our attitude and our relationships to others depend on the type of our interest in the erogenous oral, anal, and sexual zones of the body (Freud, 1905). Furthermore, at the end of his life, Freud (1938) emphasized the "splitting" of the ego itself, thus establishing the impossibility of thinking of the human subject in terms of a well-defined unity. Lacan, who, like Freud, never used the notion of self, was the first to systematically characterize this heterogeneity of the talking being. Lacan's contribution is mainly based on his elaboration of two notions: specular image and object-a. While Lacan's conception on specular image and the mirror phase may be found in his Écrits (Lacan, 1966a, 1966c), most of his developments on object-a are to be found in his seminars - in particular L'objet de la psychanalyse (Lacan, 1965) and L'angoisse (Lacan, 2004b), the complete edition of which is not yet available. ${ }^{1}$ For this reason, we will begin with a brief overview of this contribution.

\section{Lacan, specular image, and narcissism}

Lacan gave two presentations on narcissism and specular image (see Guillerault, 2003, pp. 267-272), in two sessions - 1936 and 1949 - of the International Congress of Psychoanalysis, It was not until 1966 that the 1949 text was published under the title "Le stade du miroir comme formateur de la fonction du Je telle qu'elle nous est révélée dans l'expérience psychanalytique" (Lacan, 1966c), but Lacan unceasingly worked on his concept of body image and narcissism, in particular in his seminar on anguish (Lacan, 2004b).

\footnotetext{
${ }^{1}$ The title of the seminar, "L'angoisse," is generally translated as "Anxiety." However, in this chapter, we will use the term anguish to distinguish it from the more phenomenological/psychological connotations of the term anxiety.
} 
Lacan made a crucial advance when he proposed a well-founded theory to explain how autoeroticism may be replaced by narcissism - a point that Freud (1914) had left unexplained. This advance is based on a reinterpretation of Wallon's 1931 article devoted to the process whereby "children develop the notion of their own body." Lacan called this process the mirror phase and reread Wallon's observations in terms of identification: for him, during the mirror phase, the body passes from a real state (fragmented body) to an imaginary register (virtual image). Lacan emphasized that this identification, which takes place during the mirror phase, is crucial for subjectivity: he employed the term identification in its literal sense, i.e., "the transformation which happens for someone, as he adopts an image" (Lacan, 1966c/1977, p. ??), and which provides what is usually called an identity. The human subject thus identifies himself as an image (imaginary identification). This image is the image of a complete body, erected, seen as a whole. In addition to this, the words spoken by adults indicate and acknowledge the body as being that of the child; these words, and in particular the child's personal name, are symbolic elements. This intertwining between the child's image - together his and the one he receives from the mirror - and his proper name constitutes a symbolic identification. Indeed, the proper name of a human subject designates the desire that parents attach to the person and the body of their child. This implies that the "positive" aspect of symbolic identification (being named) is linked to a "negative" phenomenon since the child is at first no more than a representative of the parents' desire, and ignorant of the content of this desire. Due to this symbolic identification, specular image not only belongs to a virtual register, it also represents a desiring subject.

Winnicott (1967) has developed a conception close to Lacan's one, when insisting upon the crucial role of the regard of the mother in the structuring of what he called the self. Lacan (1966a) emphasized that this regard is related to those symbolic elements that make a symbolic identification-validated by the proper name-possible. This process makes the infant a human subject, who apprehends his body as a whole, similar in its form to other people's bodies, while it is his own body recorded in filiation and sexual belonging. In this imaginary and symbolic representation, the real, organic body is ignored. However, the body does participate in a crucial mode-although it is a mode not involved in representation - in the constitution of individual identity. This participation does not rely on the physiological properties of the body; rather, it depends on the ability of certain bodily parts or products to be used in language processes to symbolize our relationship to the Other. ${ }^{2}$ This participation is what Lacan called objet-a, a notion he considered his major contribution to psychoanalysis.

\section{Lacan, the body, and the object-a}

While Freud (1914) focused on the fact that we love our body, Lacan differentiated two intertwined aspects of this libido attached to the body. He insisted that, on the one hand, the human subject is fascinated by the human form (Lacan, 1966c), and, on the other, that his body supposedly represents something for an other, and more basically for the Other-that is, it is necessarily experienced, in a positive or a negative light, as an object of desire (Lacan, 1977b). Lacan qualified this latter aspect of the psychic correlates of body representation as real insofar as it is not reducible to its symbolic or imaginary aspects: what I represent for the Other and his desire is precisely that which I cannot master or have clear knowledge of. In other words, a narcissistically cathected body represents the subject's question regarding his ability to please, to suit the Other's regard, the Other's demand or desire. This enigmatic value, this $x$, is what Lacan called object- $a$ (Lacan, 1977b, 2004b). The suitable object for the other's desire or demand, although it remains basically out of reach, may yet be evoked, according to Lacan, through four fundamental aspects: the breast, the feces, the regard, and the voice - that is, bodily parts or products involved in the mother-child relationship. Two of these aspects of object-a (breast and feces) are among the Freudian libidinal objects (Freud, 1905), while the two others (regard and voice) are the focus of Freudian drives (see Freud, 1915a). Lacan's crucial contribution is, first, to show that the symbolic value of these bodily parts and products, and not only their involvement in relations to others, affective life, or stages of bodily education, is what makes the corresponding body areas erogenous (Lacan, 1977b): the mouth is the area where food and love are demanded the Other, the eye and the ear are the areas receiving the expression of the Other's demand or desire through regard or voice, the anus is the area to which the Other addresses his demand.?

\footnotetext{
${ }^{2}$ Lacan distinguishes between two kinds of otherness: the other- that is, the fellow creature, whose form is fixed by identification to mirror image - and the Other - that is, the language determinations that constitute the subject, while being alien to him or her (Thibierge, 1999b, 2007). Even before a person's birth, the Other in language registers the subject at a certain place and assigns symbolic marks to the subject. Being radically alien to the child (because of the incest prohibition), and the first to symbolically represent the child in her words and her relation to it, the mother is the first incarnation of the Other.
} 
Second, and above all, the fundamental property of the object-a is a negative property, that of lacking, of not being present in body image. This absence, which may appear as a primordial irreducible loss, is designated by psychoanalysis as castration (Lacan, 1977b). As indicated above, this irreducible loss is not without relationship to symbolic identification. If Lacan designates the object by a simple letter, $a$, it is precisely to emphasize that it results from the loss that language in itself and concretely presupposes - the loss of any direct relationship to the target of desire. It is also why this object is not objectively definable: it is the principle of what gives relations to others their value, as far as these relations involve the phallus - that is, the desire as sexual. Only this implication of the phallus as a symbolic element, as a signifier (Lacan, 1977a), brings to the objects of our world their significant value.

\section{Body image and object-a in the psychopathology of everyday life and in neurosis}

The object-a can be said to be always the same, unique for each subject: psychoanalysis of neurotic patients demonstrates that each of us repetitively displays a specific, singular relationship to the others and to the Other. This relationship expresses itself through our language - that is, the way we talk (more precisely, the way our body talks), through our dreams, our symptoms, and our parapraxes. The style and structure of this relationship refer to our specific bond to the object-a-to the object's form that we have elected at the earliest times of our life. While this specific bond is what characterizes our personal identity, we spontaneously do not identify ourselves as dependent on an object but as a named image. Here we propose to call this incomplete spontaneous, intuitive operation (which we also use regarding other people) recognition. More generally, recognition refers to everything that, without receiving special attention, presents itself under the heading of reality (Thibierge, 1999b, 2007). When this is no longer the case, when some part of reality is no longer recognized, this failure manifests itself through feelings ranging from a fleeting discomfort barely tinged with anxiety - for example, the fact of no longer recognizing a common word when reading - to a complete falling apart of reality. These feelings belong to a series that ranges from Freudian "uncanny" (Freud, 1919) to depersonalization, including various feelings of strangeness that have been described in classical psychiatry (for reference, see Thibierge, 1999a, 1999b). The disorganization of body image is quite common not only in hysteria (see, for example, Freud,
1893), but also in obsessional neurosis (see Séglas, 1895, pp. 111-139). The important point is that, whichever its neurotic style, this disorganization manifests itself in circumstances where the subject finds himself nearer than usual to precisely what he unconsciously desires (Lacan, 2004b). This indicates that all three aspects of our identity (real, imaginary, and symbolic) cannot be made conscious together and that the one that should remain unconscious is the object; it is precisely insofar as body image normally lacks object-a that this image may gain consistency and may be recognized. We propose to speak of identification of the object in those more or less pathological cases where object-a intrudes into psychic reality (Thibierge, 1999b).

Lacanian psychoanalysis thus emphasizes, contrary to our intuitive apprehension of having a unified and autonomous self, that human subjectivity is heterogeneous and "Other-dependent." It involves three levels, three registers: (1) the object, the modalities of the subject's value and of his position in relation to the Other; (2) the body image; (3) the signifiers that represent him in the symbolic order. Lacan (2004b) sums up this complex structure under the concept of specular image (see also Thibierge, 1999b, 2007). To be able to think of oneself as unified, one must be able to grasp one's image or representation as a symbol-that is, as indicating the loss, the absence, of something. Indeed, every symbol supposes the possible absence of the symbolized object. To present things schematically, we can formulate the hypothesis that in order to have a self, the following prerequisite is necessary: the lack —or in Freud's words (Freud, 1915b) the repressionof the object- $a$. It is this repression that makes - the subject's heterogeneity normally non-apparent to

him and creates his illusion of having a self. In his seminar on anguish (2004b) and his comments on Daniel Lagache's report (1966a), Lacan proposed the formula $i(a)$, to introduce a link between image and objet a. This formula designates the image $i$ as getting its consistency from an object, object-a-but an object whose absence is cloaked by this image.

\section{Body image and object-a in psychosis}

The most commonly known Lacanian concept of psychosis is based on the notion of the foreclosure of the "name-of-the-father" (Lacan, 1966b). The father being ordinarily the incarnation of a foreign element in the mother-child relationship, the father as a name (the "name-of-the-father") represents the presence, in mother's discourse, of something foreign to her, something that indicates that she is lacking an object, that 
she is a desiring subject. The "presence" in mother's discourse of this "name-of-the-father" enables the subject to identify with a desire and not an object. Psychotic subjects lack this "name-of-the-father," this "presence of absence" in mother's discourse, which is originally foreclosed. This "foreclosure" results in a failure of symbolic identification, and as a result the body image is inconsistent, not unified. Many psychiatrists and psychoanalysts, though they do not use this terminology, consider that psychosis involves a fragmentation of body image (see, e.g., Pankow, 1981; Preibe \& Röhricht, 2001). The Lacanian specificity is to claim that psychosis also implies an identification of object-a. Indeed, as mentioned above, symbolic identification normally refers to an enigmatic desire object; in psychosis, the reverse is observed: the failure of symbolic identification is linked with a positive presence - instead of an enigmatic trace of the object. These two processes - fragmentation of body image and identification of object-a - may vary in their aspects and in the modality of their association, but they are always observable together, if investigated with the appropriate method. This notion, which is often only implicit in Lacan's written texts, was first explicitly developed with Cotard syndrome by Czermak (1986) and in transsexualism by Thibierge $(1996,2007)$. It is perhaps the Fregoli syndrome (Thibierge, 1999a, $1999 b, 2007)$ that most clearly exemplifies the mutual exclusion of the identification of object-a and the recognition of body image.

\section{Fregoli syndrome}

In the Fregoli syndrome (Courbon \& Fail, 1927), the patient maintains that different people are in fact a single person who changes appearances or is in disguise and persecutes the patient. Fregoli syndrome is classified together with other syndromes - Capgras syndrome (Capgras \& Reboul-Lachaux, 1923), intermetamorphosis (Courbon \& Tusques, 1932), and the syndrome of subjective doubles (Christodoulou, 1978) - that are currently referred to as "delusional misidentification syndromes" (DMS)." ${ }^{3}$ In the current

\footnotetext{
${ }^{3}$ In Capgras delusion (or Capgras syndrome), the patient holds a delusional belief that an acquaintance, usually a spouse or other close family member, has been replaced by an identical-looking impostor. Intermetamorphosis is a delusional misidentification syndrome in which the patient confuses the identities of familiar people or feels that he is being mistaken for someone else. In the syndrome of subjective doubles, the patient believes that he has a double with the same appearance, but usually with different character traits and leading a life of its own. It is worthwhile to note that Fregoli syndrome may be associated with other DMS, in particular Capgras syndrome (Lykouras, Typaldou, Gournellis, Vaslamatzis, \& Christodoulou, 2002; Papageorgeiou et al., 2005).
}

literature, Fregoli syndrome is considered as a rather rare psychotic syndrome, whose clinical significance is its possible dangerousness (Aziz, Razik, \& Donn, 2005), when, as in the princeps case, the patient eventually attacks the persecutor (Courbon \& Fail, 1927). The rarity of Fregoli syndrome is questionable, since Mojtabai (1998) has shown that misidentification syndromes are often misidentified and that their characteristics may be found in many cases of psychosis, including schizophrenia. For example, in Schreber's self-report case, one finds vivid examples that appear to be close to the Fregoli syndrome (Schreber, 2001, chapter 8).

Since the 1920s, the Fregoli and/or Capgras syndromes have been given a variety of names: falserecognition illusions of the insane ("illusion de fausse reconnaissance des aliénés"), systematic misapprehensions ("méconnaissances systématiques"), identification agnosia ("agnosie d'identification"), delirious identification ("identification délirante"). We have not drawn up this list for its historical interest but, rather, to indicate a trait that all these syndromes have in common - that is, they seem to create a kind of vacillation in the psychiatrist's mind. While there is no doubt regarding the delirious nature of the patients' belief, the nature of their illusions is not clear: how is it possible that patients are so sure of the hidden identity of the people they meet, while at the same time acknowledging that their appearances, their images, are multiple?

\section{Psychodynamic interpretations of DMS}

The fact that misidentification syndromes very often concern subjectively significant figures - for example, Weinstein (1994) notes that Courbon \& Fail's patient, who felt persecuted by an actress, was herself a wouldbe actress - has led to a variety of psychodynamic Freudian or Kleinian interpretations. However, these interpretations mainly address the Capgras syndrome; they often envisage the Capgras syndrome as separating the loved, good vs. bad, hated or neutral vs. libidinal aspects of the duplicated relatives (de Pauw, 1994), thus applying a neurotic interpretation grid to psychotic patients.

\section{DMS and right hemispheric lesions. DMS and face-recognition disorders}

Neither Fregoli syndrome nor other DMS are neurological diseases. Several arguments converge to suggest that right brain-structures dysfunction might be involved in Fregoli and other DMS, but it should be underlined that there is no evidence for a tight relation- 
ship between specified brain lesions and DMS.

DMS syndromes are known to occur in the outcome of right hemisphere strokes (Cutting, 1991); there is also a variety of evidence of right hemisphere dysfunction in schizophrenia (Cutting, 1994; Torrey, 2007). However, the relation between DMS and right hemisphere lesions is rather loose. Some evidence suggests that DMS or DMS-like cases where a neuroanatomical lesion is not identified (Förstl, Almeida, Burns, \& Howard, 1991) may be observed in other neurophysiological anomalies (e.g., toxic or metabolic diffuse brain alterations). Clinical observations of Fregoli syndrome after right hemispheric stroke may be found in the literature. On the one hand, one of us (Morin, 1997) has observed a patient who, after her right hemispheric stroke, not only made false recognitions, but also identified the same woman - a familial auxiliary who helped her when returning home-under the appeareances of a variety of neighbors and carers. She feared that this woman wanted to marry her own husband. The life history of the patient did not indicate any sign of psychosis before. It should be emphasized that, instead of being convinced of her illusions, the patient was puzzled by her strange ideas and asked "Am I going to become crazy?" In other words, this misidentification syndrome was clearly consecutive to the stroke, but it was only a "Fregoli-like" syndrome. On the other hand, de Pauw, Szulecka, and Poltock (1987) described a very typical case of Fregoli syndrome after right hemispheric infarct; however, although the authors consider that the patient was not schizophrenic before her stroke, the history they report might suggest a paranoid psychic structure.

In brain lesions, neurological face-recognition disorders (prosopagnosia) are known to appear in relation to right hemisphere lesions (see Sorger, Goebel, Schiltz, \& Rossion, 2007). This explains why the current neuroscientific studies of DMS are based on the assumption that DMS might involve a disturbance in the cognitive ability to recognize faces, face recognition being an essential component of people recognition. ${ }^{4}$ Indeed, neuropsychological tests have demonstrated that Capgras syndrome may involve neuropsychological disorders in face recognition (Lykouras et al., 2002; Papageorgiou, Ventouras, Lykouras, Uzunoglu \& Christodoulou, 2003). The Fregoli syndrome and psychotic syndromes without delusions also involve

\footnotetext{
${ }^{4}$ However, recognizing people does not only consist of face recognition. In addition, DMS patients do not especially characterize their persecutor's faces. Capgras' princeps patient gave herself several names and described herself not by her face traits but by her clothes (Capgras \&
} $\underline{\text { Reboul-Lachaux, 1923) }}$ specific face-recognition disorders, but only DMS patients show alterations of familiar-faces recognition (Edelstyn, Oyebode, Booker, \& Humphreys, 1998). Face-recognition disorders in DMS have led to a variety of hypotheses. Face recognition involves two neuropsychological processes with two different brain networks: a neutral one (which is disturbed in prosopagnosia), and an emotional one involving the limbic system (Ellis \& Lewis, 2001). Emotional recognition is maintained in prosopagnosia, as shown by the persistence of emotional reactions to unrecognized familiar faces in prosopagnosic patients (Bauer, 1984). It has therefore been proposed that the affective component of face recognition should be unavailable in DMS (Ellis \& Lewis, 2001), in particular in Capgras syndrome. However, this model is not easily applicable to Fregoli syndrome. These studies have the interest of investigating the neurological substrates necessary for a normal recognition of familiar and unfamiliar faces. However, increasingly complicated models of face recognition are needed (Ellis \& Lewis, 2001) to account for the faith that patients have in their delusions, without leading to conclusive results. It should also be underlined that Fregoli and Capgras patients exhibit similar difficulties in visuospatial or face-recognition tasks, whereas their clinical symptoms are different.

Indeed, cognitive theories do not address the problem of either the persecutory value of the misidentified people or the faith that psychotic patients have in their false recognitions. To be schematic, one could say that these studies do not address the problem of the nature of delusory misidentifications. Disclosing the nature of a psychic syndrome means wondering whether it has a subjective intrinsic significance - that is, whether its component symptoms are linked together, and whether various modulations of these links may be described in several normal or pathological circumstances. ${ }^{5}$ In particular, isolating the symptoms that constitute a syndrome may be misleading (Mojtabai \& Rieder, 1998). The specificity of psychoanalysis is to consider the intrinsic logic of the patients' discourse and behavior and not to interpret them as revealing perceptive or cognitive defects. First, describing and, then, understanding a psychic syndrome must be addressed by specific methods. These methods involve describing and analyzing the significant aspects of patients' discourse and behavior. Such an analysis must rely in particular on complete and accurate reports of the patients' words. Clinical reports from the early twentieth century have made such discourses available; such discourses are

\footnotetext{
${ }^{5}$ For example, this is the way Freud (1914) tried to understand the significance of narcissism and its avatars in neurosis and psychosis.
} 
also available in some psychiatric observations currently made by psychoanalysts interested in psychotic disorders of specular image (Porge, 1986; Thibierge, 1999b).

\section{The significance of DMS}

The question of the significance of delusory misidentifications has been addressed by Cutting (1991), who proposed that the common feature of DMS (whether or not they involve people recognition) was a problem with uniqueness, with identity. This is an invitation to using Lacanian psychoanalysis, since Lacan's oeuvre contains many dispersed contributions to the differentiation between perception or recognition and identification (see, e.g., Lacan, 1966b, 2002). These contributions have been systematized at length elsewhere (Thibierge, 1999b). We will develop this contribution on the basis of psychiatric and neurological cases. First, we present three Fregoli cases - the princeps case and two modern observations, Case A and Case B. Case A is a typical Fregoli syndrome. Case B illustrates the possible occurrence of Fregoli traits in a psychotic patient with paranoid personality disorder. Neither Case A nor Case B had neuroimaging or cognitive explorations. We then show that somatoparaphrenia, a symptom of right hemisphere brain damage, also involves dissociation of recognition and identification.

\section{The Fregoli syndrome: a Lacanian perspective}

\section{The Fregoli princeps case}

In 1927, Paul Courbon and Gabriel Fail named Fregoli syndrome a disorder observed in a female patient they considered "schizophrenic." The name "Fregoli" was used by the patient herself: she insisted that her main persecutor, the actress Robine, was able, just like the famous Italian actor Fregoli, to embody a multitude of different characters. The patient thus saw Robine in the people she met. These people were Robine in disguise. However, the patient never said that these disguised figures had identical faces. She insisted, rather, that although their appearances differed, they were always the same person, "only one being" (Courbon \& Fail, 1927). This being was responsible for a variety of imposed phenomenadirected at the patient-magnetic powers, outbursts, obscene commands, etc. For example, among the imposed actions falling on her, the patient should masturbate herself. These masturbatory acts resulted in harmoniously shadowing Robine's eyes, while destroying the patient's own body. The patient's right index finger, through which Robine thus increased her beauty, therefore cost several millions francs.

\section{Case $A$}

Porge (1986) has described a similar case: a female patient had felt at a glance that she loved a man, "Peter." She met him once thereafter, but she was not sure that it was him - she thought it could have been someone else. After this meeting, she always thought about Peter, and believed he wanted her to reach him. Indeed, she "saw" him in the various men she met: Philip, John, Simon, ... Each time, she knew for sure that this was Peter, but Peter as a transformed person. She knew it for sure, because she felt attracted to these different men. In fact, each of them was Peter. Moreover, she felt that Peter had stolen one of her lips: he used her upper lip when speaking (the lower lip being still hers), so that she was obliged to speak "with a small voice," which was Peter's voice as well. As we can see, in this case this is always the one and the same being, Peter, who takes on the appearance of other men (the men she loves), who commands (attracts) her, and who steals a part of her body (her upper lip belongs to him).

\section{Case B: Fregoli traits in a paranoiac patient}

The position of the Fregoli syndrome in the psychopathology of psychosis is an interesting one: on the one hand, this syndrome is linked to "paranoid" symptoms; on the other, some characteristic aspects of Fregoli syndrome may be observed in cases that are not classified either as misidentification syndromes or as monothematic delusions (Mojtabai, 1998). Thibierge (1999b) has reported the case of a patient with paranoid personality disorder whose persecutor did not exactly take the appearance of other persons but managed to alter the patient's appearance or to command other persons to appear. This female patient described how her life was made difficult by a long-standing conflict with a nun who had been one of her teachers in childhood and who had been persecuting her since then. This nun sometimes managed to command persons to enter the patient's house, unseen by anybody but her. She caused the patient to be mistaken for someone else in the small town where she lived. The patient could hear the nun's voice giving orders to her husband or members of her family, or even speaking from some parts of her body (hand, eye, foot). The voice also talked to people on TV, making them turn their faces to her. The nun thus changed her appearances, her names, impersonated various persons, sometimes taking the 
place of the patient herself. She guided and controlled, through her voice or her gaze, what the patient called "les humaines" - the human appearances of persons.

In this case, as in the one reported by Porge and as in the princeps case, the persecutor's name refers to the one and the same being who causes various changes of human appearance, who commands those appearances, and who partly controls and takes possession of the body of the patient him- or herself.

\section{Fregoli syndrome, specular image, and object-a}

Fregoli syndrome may be read as revealing a profound alteration of the normal relationships between specular image and object-a. This alteration may be characterized in two ways. First, when meeting a human figure, the subject always identifies an " $x$," which he names by saying: "it is Robine," "it is Peter," "it is the nun." The image may change, the subject knows that the appearance is not the same, but in fact, it is soand-so, it is in fact always the same persecutor, pursuing the subject. Neither Courbon \& Fail's patient nor Porge's or Thibierge's reported patients ever said that people they met had the same appearance; what they said was that they were the same being, or images commanded by the same being, the same $x$ designated by a single name - although different, the same: the other is always the same.

A second trait of Fregoli syndrome is that the patient's own body image is broken up: the patient's own index finger, lower lip, or right hand are shared with the persecutor's image. The " $x$-identification" of one unique being is thus associated with a fragmentation of the representation the patient gives of his or her own body.

What stands out in Fregoli syndrome is decomposition of the fundamental elements involved in the recognition of people, and also in self-recognition. This decomposition makes it possible for two major different dimensions of recognition to appear separately one from another: the name, and the image. In the words of these patients, the name designates something that the image fails to cover, to represent - that is, something of which the image does not allow recognition. It is something else, something that is tainted with persecutory tones.

Lacanian theory offers an economic way of characterizing this something else, this $x$, and the organization of the triad it forms with name and body image.

According to what the patient says, $x$ appears to be something that is:

- autonomous, obeying only its own determinants
- xenopathic - that is, imposing various sensorial phenomena on the patient

- at the source of a disintegration of the body image

- one (always the same).

In place of the image and instead of it, the subject always identifies the same $x$. Recognition, and especially recognition of the image of one's own body, is altered. The body image is fragmented, broken up into its components, for the benefit of something that the patient names and hence positively identifies. These characteristics correspond to what Lacan designated as the object- $a$. If we rely on Lacan's formula $i(a)$ to characterize normal body image (Lacan, 1966a), we must conclude that the bond between image and object is altered or suppressed in the case of the Fregoli syndrome. The structure of the specular image is thus broken down into separate elements, which are clearly disjointed: first, the body image is dislocated; second, there is the recurrent return of an object that, in this case, is not repressed, not "lost" - not missing - but identified and always identically named by the subject. We can thus advance the hypothesis that the formula $i(a)$ - which concretely refers to a bond between elements - does not characterize the psychotic pathologies cited above. Instead, in these cases, the object-a is unveiled, the image is undone, dislocated, and the identification with an image is impossible. Indeed, the image and the object are isolated from one another.

The Fregoli illusion syndrome illustrates in structural terms the fundamental dimensions of subjectivity. In this syndrome, these terms - the name, the object (object-a), and the image - that are normally intertwined to such a point that their heterogeneity is invisible, are isolated with great precision. The proper name takes on the function of both a common noun and a unique name. It is the persecutor's name, identified with the "others" met by the subject, and even with the disjointed elements of the subject's own body. This unique name, which rules and prevails over the usual function of the proper name, "names" an $x$ that has the property of coming back to the subject under the guise of a real and unequivocal identity, the identity of an imposed meaning. This indicates the failure of the operation symbolized by naming. Indeed, the normal function of naming is not only to allow designation by

\footnotetext{
${ }^{6}$ We have already mentioned that our way of investigation in this paper, and more generally in our work relating to specular image problems, does not ignore what Lacan called the name-of-the-father's foreclosure. But as we explained, we try to go from body-image problems to their conditions, especially the failure of proper-name operation. There is no doubt, however, that this failure is conditioned by the foreclosure of the name-of-the-father.
} 
a symbol, but also to identify the subject himself in a symbolic - differential-mode. In Fregoli syndrome, naming is governed by a sole name identifying the object; this object is then reduced to a single remaining name, always the same. The link between name and object clearly appears in a case reported by Thibierge (1999b). A recently divorced woman found herself in the situation of losing her husband's family name. Right at the time she lost her husband's name, she expressed a typical Fregoli syndrome: the men she saw in the street or in everyday life were various appearances of her husband, and the women she met were, in fact, her disguised daughter. While in neurosis the object-a is in principle never identified, in the psychotic cases described above, this object constitutes the mainspring of the systematization of the delirium. The unifying efficacy of body image is absent; the others' image may not be apprehended in the field of recognition. Its only consistency is to be found in the words of the patient, which create a persecutor in the imaginary register. Clearly, the Fregoli syndrome thus presents in a state of separation, as in a chemical analysis, something our clinical experience of neurosis cannot provide. True, the same object repetitively drives the neurotic's quest. But because of repression, the neurotic subject can never identify this object except through the resulting anxiety, which may perhaps indicate its incidence. This is the price to pay for maintaining the possibility of recognition.

\section{Somatoparaphrenia: a Lacanian perspective}

Another type of separation between $i$ and a may be found in a rare neurological disorder of body imagenamely, somatoparaphrenia (Morin \& Thibierge, 2004; Morin, Thibierge, Bruguière, Pradat-Diehl, \& Mazevet, 2005). While persisting left hemineglect (lack of attention or interest to stimuli in the left hemispace and/ or hemibody) is very commonly observed after right hemisphere lesions (Heilman, Valenstein, \& Watson, 2000), asomatognosia is a rare symptom temporarily observed after extensive right hemispheric lesions (see Lhermitte, 1939). In this symptom, the patients do not recognize their left paralyzed arm as their own. Asomatognosia may be accompanied by productive symptoms that Gertsmann (1942)called somatoparaphrenia: assimilation of paralyzed limbs to an inanimate, cumbersome, or supernumerary object, or personification of the paralyzed limbs. This assimilation to a person or to an object is often colored with hatred or scorn; this led Critchley (1962) to coin the term "misoplegia." Somatoparaphrenia is subject to many different psycho- logical interpretations. Halligan, Marshall, and Wade (1995) and Feinberg (2001) consider it to be a rationalization that allows patients to cope with the traumatic failure of their body schema, or to express feelings regarding their own present situation. Other authors consider somatoparaphrenia as completely meaningless productions (Laplane, 1998). Nevertheless, these productions display recurrent themes, which are stable in a given patient and may be very similar from one patient to another.

We have published several observations, the analysis of which demonstrated that the object-a appears in the discourse or behavior of patients suffering from somatoparaphrenia. Patient PR (Morin et al., 2001), who suffered from persistent and invalidating hemineglect, described his problems not in terms of space processing disorders, but in terms of a variety of disorders that he mentioned as belonging to the same series: on the one hand, body-image disorders (having "holes in his body"); on the other, problems with the oral object - precipitation in eating and speaking, unceasing and urgent demands to his wife. Two patients attributed oral characteristics to their left hand (Morin et al., 2002). Patient QR explained that he had seen "a left arm passing" and that he had "felt like biting" this arm. Patient DN, a right-handed man, kissed his interlocutor's hand "because I can't shake hands" and gave the same reason for having drawn enormous lips besides his self-portrait. In three women, we observed a "little daughter personification" (Morin et al., 2005). MN, a childless woman aged 69, "invented a scenario" that, she said, "comforted" her: her left hand was a daughter of hers, who was born on the day when her stroke had happened and who lay in the armrest of the wheelchair as in a cradle. She gave this daughter a name: she called her "Leaf." Another patient, MM, said that her hand wore the "name of her husband" and described its childish behavior: "It plays during night and rests in the daytime, it is a lazy bones." "In the night, it comes stealing under me and scratches me." "It is probably angry with me for not taking care of it." Another patient, DS, when asked about her children, vigorously shook her paralyzed arm and said: "Lily, say good morning." This patient had previously been temporarily convinced that her left hand was that of her daughter Lily, which "had remained pasted after a cuddle," and at the same time she did not recognize the true Lily ("that is not my daughter"). All these cases show the association between, first, a splitting of body image (lips besides the face) and a confusion with others' body image, and, second, traits that call to mind an animate/inanimate object (child-leaf), independent body parts (a passing arm, a pasted arm), sometimes 
with a personal life (it worked too much, it is angry for not being taken care of). These traits belong to the category called "uncanny" by Freud (1919); according to Lacan (2004b), the feeling of "uncanny" provides evidence of the appearance of the normally repressed object-a in the foreground. ${ }^{7}$ The modalities of this appearance of object-a correspond with what we know of the determinants of object-a in men and women: while orality is related to object-a in both sexes, children may have an object-a status in women (Freud, 1933; Lacan, 2004a). Furthermore, case DS clearly illustrates the mutual incompatibility underscored by Thibierge (1999b) between perceiving (i.e., recognizing) reality and identifying the object. All these cases are characterized by an alteration of specular image: (1) the patient's body has lost its unity and its individuality to such an extent that the arm can be given a personal name, as in the case of $\mathrm{MN}$, and (2) the object that should be lacking due to repression and triggering desire intrudes into the psychic reality of the patient. ${ }^{8}$

Thus, in neurological disorders of body image, we find the same combination as in psychosis: an overly present object (somatoparaphrenia in neurological cases, persecutor's influences in the Fregoli syndrome, organ negation in the Cotard syndrome) combined with body-image disorders (anosognosia for hemiplegia and asomatognosia in neurological cases, delirium of enormity or extreme smallness in Cotard syndrome, false recognition in Fregoli and Capgras syndromes) and with a failure of naming (deterioration of the proper name in Fregoli syndrome, personification of the hand in somatoparaphrenia).

This strongly supports the hypothesis proposed by Thibierge (1999a, 1999b) that the stability of body image and the neutralization of the object-a are mutually

\footnotetext{
${ }^{7}$ It should be noted that the object appears at the very place of the loss involved by left hemiplegia - the paralysis of the left arm. This should be put in relation with a case reported by Lacan (1953). A patient "whose ego development had been impaired by an obstetrical brachial plexus palsy of the left arm"-i.e., a left paralysis without any brain lesion-reported "a dream in which the rectum appeared in the left part of the thorax." In this case, a body part related to anality broke up the body image by appearing on the paralyzed side of the patient. This however happened as a dream-i.e., the appearance of the object needed an artefactual release of repression-whereas in the cases presented in this paper, it manifests itself spontaneously, due to right hemispheric lesions.

${ }^{8}$ It should be emphasized that this neurological alteration of specular image did not seem to be accompanied by any alteration in the patients' identification traits: as emerged from interviews with the patients (see Morin et al., 2005) or their relatives, the patients continued to express the same neurotic behavior and complaints as they did before their stroke. Besides, the persistence of a strong "feeling of identity" has been observed in patients with RHS (Morin, 2009). These data show that one may feel oneself a unique, coherent, and stable individual while suffering dramatic neurological disturbances of body image.
}

exclusive. The question then arises: can we describe a functional neuroanatomy of such a mutually exclusive relationship? In other words, to use the term proposed by Vogeley (Newen \& Vogeley, 2003) and Legrand $(\underline{2003})$, is there a "neural signature" of the relations,

between object-a and image?

\section{Right hemisphere and object-a}

The "evanescent," "virtual" characteristics of objecta make it difficult to look for its "neural signature." However, it could be noted that, in partial epilepsy, paroxystic right hemisphere activity arouses body representations involved in the first mother-child relationships. During such seizures (Loddenkemper \& Kotagal, 2005), the patients may spit, vomit, need to urinate or defecate, drink, or dispense kisses with religious or friendly effusion.

\section{Right hemisphere and body image}

As seen above (see Torrey, 2007), on the one hand, right hemisphere dysfunction can be observed in both psychotic and neurologic body-image disorders, and, on the other, neuroimaging explorations have found right hemispheric anomalies in schizophrenic patients. ${ }^{9}$ Neuroimaging studies show that the right hemisphere is involved in a variety of behavioral or mental activities that have to do with recognizing oneself and other people: the right hemisphere is activated when normal subjects react to the human body form (Downing, Bray, Rogers, \& Childs, 2004), to self and others' images (Decety \& Sommerville, 2003), and to their first name (Perrin et al., 2005). The right parietal lobe is involved in agency (i.e., distinguishing between own and others' actions), in empathy (i.e., recognizing and sharing emotions of other people; see Decety \& Lamm, 2007), and in tasks exploring the capacity to attribute beliefs, desires, or other attitudes to others ("mindreading" or "theory of mind"; see Newen \& Vogeley, 2003). The data listed above show that the integrity of right hemisphere structures is necessary to ensure the stability of body image. The right hemisphere is not the only brain area involved in maintaining a stable and individualized body image. Interestingly, in none of

\footnotetext{
${ }^{9}$ However, these data do not allow us to conclude on the direct/indirect or cause/consequence status of the relationship between right hemisphere dysfunction and DMS. Therefore, the links between psychosis and neuropsychological disorders remain an open question.
} 
our three cases of somatoparaphrenia were we able to affirm that the brain suffered a unique lesion; all three patients had or might have had extended or multiple lesions. Indeed, the model of "neural signature of the self" proposed by Newen and Vogeley (2003) involves medial cortical parietal regions and inferior parietal and temporoparietal cortices bilaterally.

The exploration of brain activity during depersonalization and autoscopic phenomena may also contribute to this discussion, insofar as these symptoms involve pathological alterations of the patients' specular image: depersonalization (Schilder, 1914) is characterized by subjective experiences of unreality and detachment in one's sense of self, while in autoscopic phenomena, the patient may see his body image outside his own body and wonder in which of these bodies his self "resides" (Blanke, Landis, Spinelli, \& Seeck, 2004). Paroxystic episodes of depersonalization (Lambert, Sierra, Phillips, \& David, 2002) involve activity of right and more often left temporal lobes. Autoscopic phenomena (Blanke et al., 2004) are often linked to paroxystic activation of the right or left temporoparietal junction. This suggests that the stability of body image necessitates the integrity of a variety of brain circuits, including right hemisphere and interhemispheric connections (see Ramachandran \& Blakeslee, 1999). From the data cited above, we obtained a list of cognitive function related to a variety of aspects of self-representation. However, this did not bring any knowledge regarding the cerebral circuits whose activation or inhibition might guarantee our ordinary certitude of being unique and autonomous individuals. Indeed, this certitude being a permanent state, it escapes most of the current neuroimaging techniques, which consist of comparing a supposed resting state with specified short-duration mental activities. In other words, there is no neural signature of the self known today, this dead end meeting the more general difficulty of identifying the brain substrate of consciousness.

\section{Conclusion}

Our ordinary certitude of having a self is linked to the stability of body image. Brain imagery permits one to list a variety of brain structures (including several right hemisphere areas) whose integrity is necessary to maintaining this stability. Nevertheless, this inventory does not permit one to situate the source of our certitude to have a self. Psychoanalysis brings to light a "psychic anatomy of the self," by showing that the stability of body image depends on the repression of the object. This mutually exclusive relationship between the consistency of body image and the presence of object-a in psychic reality - in other words, between recognition and identification - can be found in a variety of normal and pathological circumstances. This is a strong argument for considering this mutually exclusive relationship as a fundamental component of human subjectivity. This implies that all aspects of our identity cannot be made conscious at the same time. As a result, the "self" would seem to be no more than a neurotic illusion. This illusion is obviously necessary to our social life. We should, however, keep in mind that it may also be at the root of what Freud (1930) called the discontents of civilization.

\section{REFERENCES}

Aziz, M. A., Razik, G. N., \&. Donn, J. E. (2005). Dangerousness and management of Delusional Misidentification Syndrome. Psychopathology, 38: 97-102.

Bauer R. M. (1984). Autonomic recognition of names and faces in prosopagnosia: A neuropsychological application of the guilty knowledge test. Neuropsychologia, 22: 457-469.

Blanke, O., Landis, T., Spinelli, L., \& Seeck, M. (2004). Out of body experience and autoscopy of neurological origin. Brain, 127: 243-258.

Capgras, J., \& Reboul-Lachaux, J. (1923). L'illusion des “sosies" dans un délire systématisé chronique. Bulletin de la Société Clinique de Médecine Mentale, 2: 6-16.

Chemama, R. (2000). Dictionnaire de la psychanalyse. Paris: Larousse.

Christodoulou, G. N. (1978). Syndrome of subjective doubles. American Journal of Psychiatry, 135: 249-251.

Courbon, P., \& Fail, G. (1927). Syndrome d'illusion de Frégoli et schizophrénie. Bulletin de la Société Clinique de Médecine Mentale, 15: 121-125.

Courbon,P.,\&Tusques,G.(1932).Illusionsd'intermétamorphose et de charme. Annales Médico-Psychologiques, 14: 401406.

Critchley, M. (1962). Clinical investigation of disease of the parietal lobes of the brain. Medical Clinics of North America, 46: 837-857.

Cutting, J. (1991). Delusional misidentification and the role of the right hemisphere in the appreciation of identity. British Journal of Psychiatry, 159: 70-75.

Cutting, J. C. (1994). Evidence for right hemisphere dysfunction in schizophrenia. In: A. David \& J. Cutting (Eds.), The Neuropsychology of Schizophrenia. Hillsdale, NJ: Lawrence Erlbaum, pp. 231-242.

Czermak, M. (1986). Signification psychanalytique du syndrome de Cotard. In: J. Clims (Ed.), Passions de l'objet. Paris: Editions de l'Association Freudienne, pp. 205-236.

Decety, J. (2002). Naturaliser l'empathie. L'encéphale, 28: 920.

Decety, J., \& Lamm, C. (2007). The role of the right temporoparietal junction in social interaction: How low-level 
computational processes contribute to meta-cognition. Neuroscientist, 13: 580-593.

Decety, J., \& Sommerville, J. (2003). Shared representations between self and other: A social cognitive neuroscience view. Trends in Cognitive Sciences, 7: 527-533.

de Pauw, K. W. (1994). Psychodynamic approaches to the Capgras delusion: Acritical historical review. Psychopathology, 27: 154-160.

de Pauw, K. W., Szulecka, T. K., \& Poltock, T. L. (1987). Fregoli syndrome after cerebral infarction. Journal of Mental and Nervous Disease, 175: 433-437.

Downing, P. E., Bray, D., Rogers, J., \& Childs C. (2004). Bodies capture attention when nothing is expected. Cognition, 93: B27-B28.

Edelstyn, N. M. J., Oyebode, F., Booker, E., \& Humphreys, G. W. (1998). Facial processing and the delusional misidentification syndromes. Cognitive Neuropsychiatry, 3: 299-314.

Ellis, H. D., \& Lewis M. B. (2001) Capgras delusion: A window on face recognition. Trends in Cognitive Sciences, 5: 149-156.

Feinberg, T. E. (2001). Altered Egos: How the Brain Creates the Self. New York: Oxford University Press.

Förstl, H., Almeida, O. P., Burns, A., \& Howard, R. (1991). Psychiatric, neurological and medical aspects of misidentification syndromes: A review of 260 cases. Psychology and Medicine, 21: 905-910.

Freud, S. (1893). Some points for a comparative study of organic and hysterical motor paralyses. Standard Edition, 1.

Freud, S. (1905). Three Essays on the Theory of Sexuality. Standard Edition, 7: 125-243.

Freud, S (1914). On narcissism: An introduction. Standard Edition, 14: 67-102.

Freud, S. (1915a). Instincts and their vicissitudes. Standard Edition, 14: 111-140.

Freud, S. (1915b). Repression. Standard Edition, 14: 143-158.

Freud, S. (1919). The uncanny. Standard Edition, 17:219-256.

Freud, S. (1930). Civilization and Its Discontents. Standard Edition, 21: 59-145.

Freud, S. (1933). New Introductory Lectures on Psychoanalysis. Standard Edition, 22: 81-111.

Freud, S. (1938). Splitting of the ego in the process of defence. Standard Edition, 23: 275-278.

Gertsmann, J. (1942). Problems in imperception of disease and of impaired body with organic lesions. Archives of Neurology and Psychiatry, 48: 890-913.

Guillerault, G. (2003). Le miroir et la psyché. Dolto, Lacan et le stade du miroir. Paris: Gallimard.

Halligan, P. W., Marshall, J. C., \& Wade, D. T. (1995). Unilateral somatoparaphrenia after right hemispheric stroke: A case description. Cortex, 31: 173-182.

Heilman, K. M., Valenstein, E., \& Watson, R. T. (2000). Neglect and related disorders. Seminars in Neurology, 20: 463-470.

Jeannerod, M. (2003). Les troubles de la reconnaissance de soi: Une approche neuropsychologique des symptômes positifs de la schizophrénie. Médecine/Sciences, 19: 621-624.

Johnston, S. C., Baxter, L. C., Wilder, L. S., Pipe, J. G., Heiserman, J. E., \& Prigatano, G. P. (2002). Neural correlates of self-reflection. Brain, 125: 1808-1814.
Jung, C. G. (1958). The Undiscovered Self. Boston: Little, Brown \& Company.

Klein, M. (1946). Notes on some schizoid mechanisms. International Journal of Psychoanalysis, 27: 99-110.

Kohut, H. (1971). The Analysis of the Self: A Systematic Approach to the Psychoanalytic Treatment of Narcissistic Personality Disorders. New York: International Universities Press.

Lacan, J. (1953). Some reflections on the ego. International Journal of Psychoanalysis, 34: 11-17.

Lacan, J. (1965). L'objet de la psychanalyse. Unpublished seminar, Paris.

Lacan, J. (1966a). Remarques sur le rapport de Daniel Lagache. In: Écrits. Paris: Seuil, pp. 647-684.

Lacan, J. (1966b). D’une question préliminaire à tout traitement possible de la psychose. In: Écrits. Paris: Seuil, pp. 531-583.

Lacan, J. (1966c). Le stade du miroir comme formateur de la Ok as added? fonction du Je telle qu'elle nous est révélée dans l'expérience psychanalytique. In Écrits. Paris: Seuil, 1966, pp. 93-100. [The mirror stage as formative of the function of the $I$ as revealed in psychoanalytic experience. In: Ecrits: A Selection, ed. A. Sheridan. London: Tavistock/Routledge, 1977, pp. 1-7.]

Lacan, J. (1977a). The signification of the phallus. In: Ecrits: A Selection, ed. A. Sheridan. London: Tavistock/Routledge, pp. 281-291. [Originally published 1966]

Lacan, J. (1977b). The subversion of the subject and the dialectic of desire in the Freudian unconscious. In: Ecrits: A Selection, ed. A. Sheridan. London: Tavistock/Routledge, pp. 292-325. [Originally published 1966]

Lacan, J. (2002). Presentation on psychical causality. In Ecrits, ed. B. Fink. New York: W. W. Norton, pp. 123-159. [Originally published 1966]

Lacan, J. (2004a). Autres écrits. Paris: Seuil.

Lacan, J. (2004b). Le séminaire, livre 10: L'angoisse. Paris: Seuil.

Lambert, M. Y., Sierra, M., Phillips, M. C., \& David, A. S. (2002). The spectrum of depersonalization: A review plus four new cases. Journal of Neuropsychiatry and Clinical Neuroscience, 14: 141-154.

Laplane, D. (1998). L'étrange en neurologie. Etudes Psychothérapiques, 17: 23-32.

Legrand, D. (2003). How not to find the neural signature of selfconsciousness. Consciousness and Cognition, 12: 543-546.

Lhermitte, J. (1939). L 'imagedenotrecorps. Paris: L'Harmattan, 1998.

Loddenkemper T., \& Kotagal, P. (2005). Lateralizing signs during seizures in focal epilepsy. Epilepsy and Behavior, 7: $1-17$.

Lykouras, L., Typaldou, M., Gournellis, R., Vaslamatzis, G., \& Christodoulou, G. N. (2002). Coexistence of Capgras and Fregoli syndromes in a single patient: Clinical, neuroimaging and neuropsychological findings. European Psychiatry, 17: 234-235.

Mojtabai, R. (1998). Identifying misidentifications: A phenomenological study. Psychopathology, 31: 90-95.

Mojtabai, R., \& Rieder, R. O. (1998). Limitations of the symp- 
tom-oriented approach to psychiatric research. British Journal of Psychiatry, 173: 198-202.

Morin, C. (1997). Subjectivité et lésions cérébrales. L'Information Psychiatrique, 73: 927-929.

Morin, C. (2009). Sentiment d'identité et lésions cérébrales focales. Psychologie et Neuropsychiatrie du Vieillissement, 7: 21-29.

Morin, C., Durand, E., Marchal, F., Timsit, S., Manai, R., Pradat-Diehl, P., et al. (2002). Asomatognosie et troubles de l'oralité. Une lecture psychanalytique. Annales de Réadaptation et de Médecine Physique, 46: 12-23.

Morin, C., Taillefer, C., Vallat, C., Helsly, N., Thibierge, S., \& Pradat-Diehl, P. (2001). Qu'est-ce qu'un "gauche"? Annales de Réadaptation et de Médecine Physique, 44: 192-204.

Morin, C., \& Thibierge, S. (2004). L'image du corps en neurologie: de la cénesthésie à l'image spéculaire. Apports cliniques et théoriques de la psychanalyse. L'Evolution Psychiatrique, 69: 417-430.

Morin, C., Thibierge, S., Bruguière, P., Pradat-Diehl, P., \& Mazevet, D. (2005). "Daughter-somatoparaphrenia" in women with right hemisphere syndrome: A psychoanalytical perspective of neurological body knowledge disorders. Neuropsychoanalysis, 7: 171-184.

Nagel, T. (1974). What is it like to be a bat? Philosophical Review, 83: 435-450.

Newen, A., \& Vogeley, A. (2003). Self-representation: Searching for a neural signature of self-consciousness. Consciousness and Cognition, 12: 529-543.

Pankow, G. (1981). L'être-là du schizophrène. Paris: Aubier.

Papageorgiou, C., Ventouras, E., Lykouras, L., Uzunoglu, N., \& Christodoulou, G. N. (2003). Psychophysiological evidence for altered information processing in delusional misidentification syndromes. Progress in Neuro-Psychopharmacology \& Biological Psychiatry, 27: 365-372.

Perrin, F., Maquet, P., Peigneux, P., Ruby, P., Degueldre, C., Balteau, E., et al. (2005). Neural mechanisms involved in the detection of our first name: A combined ERPs and PET study. Neuropsychologia, 43: 12-19.

Porge, E. (1986). Endosser son corps. Littoral, 21: 65-88.

Preibe, S., \& Röhricht, F. (2001). Specific body image pa- thology in acute schizophrenia. Psychiatry Research, 101: 289301.

Ramachandran, V.S., \& Blakeslee, S. (1998). Phantoms in the Brain: Probing the Mysteries of Human Mind. New York: HarperCollins.

Schilder, P. (1914). Selbstbewusstsein und Persönlichkeitsbewusstsein: Eine Psychopathologische Studie. Berlin: Springer.

Schreber, D. P. (2001). Memoirs of My Nervous Illness. New York: New York Review of Books.

Séglas, J. (1895). Leçons cliniques sur les maladies mentales et nerveuses. Paris: Asselin et Houzeau.

Sheridan, A. (1977). Translator's note. In: J. Lacan, Ecrits: A Selection. Bristol: Routledge, pp. vii-xii.

Sorger, B., Goebel, R., Schiltz, C., \& Rossion, B. (2007). Understanding the functional neuroanatomy of acquired prosopagnosia. NeuroImage, 35: 836-852.

Thibierge, S. (1996). Proximité du transsexualisme et du syndrome de Frégoli en clinique et en doctrine. In: Sur l'identité sexuelle. À propos du transsexualisme. Paris: Editions de l'Association Freudienne Internationale, pp. 489-498.

Thibierge, S. (1999a). L'image et le double. La fonction spéculaire en pathologie. Paris: Erès.

Thibierge, S. (1999b). Pathologie de l'image du corps. Etude des troubles de la reconnaissance et de la nomination en psychopathologie. Paris: Presses Universitaires de France.

Thibierge, S. (2007). Clinique de l'identité. Paris: Presses Universitaires de France.

Torrey, E. F. (2007). Schizophrenia and the inferior parietal lobule. Schizophrenia Research, 97: 215-225.

Vogeley, K., \& Fink, G. E. (2003). Neural correlates of the firstperson perspective. Trends in Cognitive Sciences, 7: 38-42.

Wallon, H. (1931). Comment se développe chez l'enfant la notion du corps propre. Journal de Psychologie, 28: 705-748.

Weinstein, E. A. (1994). The classification of delusional misidentification syndromes. Psychopathology, 27: 130-135.

Winnicott, D. W. (1967). Mirror role of mother and family in child development. In: Playing and Reality (pp. 111-118). London: Routledge, 1971. 
